\title{
Limit spans of cable and arch structures
}

\author{
P. Latteur ${ }^{1} \&$ W. P. De Wilde ${ }^{2}$ \\ ${ }^{1}$ Tractebel Engineering, Belgium \\ ${ }^{2}$ Vrije Universiteit Brussel (VUB), Belgium
}

\begin{abstract}
The limit span is reached when a structure cannot bear any other load than its self-weight, while the maximum resistance of the material or an excessive deflection is reached. Former publications have shown that the indicators of volume $\mathrm{W}$ and of displacement $\Delta$ are dimensionless numbers which allow optimizing efficiently the strength and self-weight or the stiffness of structures. In this context, this survey establishes the analytical expressions of limit spans of cables and arches.

Keywords: limit span, maximum span, ultimate span, self-weight, deflections, limit, buckling, volume, morphological indicators, indicator of volume, indicator of displacement.
\end{abstract}

\section{Introduction}

During the last decades, structures with ever increasing spans have been designed: e.g. the Viaduct of Millau (France), a technological and scientific masterwork, is a perfect illustration of this statement.

It is thus perfectly legitimate to ask oneself: "what are the theoretical limits of structural spans?", and also "what are the factors influencing this limit?"

The latter question is not trivial as the answer depends on the typology of the structure: a beam is subject to bending, an arch to compression, a cable only works in traction and one finds both compression and traction in trusses.

Considering the specifications of the Eurocodes, defining performances of a structure from both points of view of strength (ultimate limit state, in short ULS) and stiffness (serviceability limit state or SLS), and taking into account local instability phenomena (buckling), one can distinguish between: 
- strength limit span, reached when the material strength is exceeded under the self-weight of the structure;

- stiffness limit span, reached when the maximum deflection, under selfweight, is exceeded, or when instability phenomena occur.

By material strength one has to think in terms of yield stress (e.g. for steel) or ultimate strength: one is then thinking of an "ultimate limit span". The considered strength will be noted as $\sigma$. In order to establish the subsequent diagrams, one considered:

- for VHS steel: $\quad \sigma=1000 \mathrm{Mpa}$

- for HS steel: $\quad \sigma=300 \mathrm{Mpa}$;

- for mild steel: $\quad \sigma=140 \mathrm{Mpa}$

(VHS: very high yield strength steel)

- for aluminium: $\quad \sigma=55 \mathrm{Mpa}$

- for timber: $\quad \sigma=10 \mathrm{Mpa}$

- for reinforced $(\mathrm{RC})$ or prestressed concrete (PC): $\sigma=15 \mathrm{Mpa}$.

Generalizing the concept of limit span, one could define it as the maximum span a structure can withstand, sustaining its self-weight, plus a given load F.

To establish those limit spans the authors make use of the theory of so-called "morphological indicators", developed in the context of arches in [1-3].

A morphological indicator is a number which has three characteristics:

- $\quad$ it is a dimensionless number

- it is the image of a physical value (volume of material, stiffness of a structure...)

- its value depends on the overall geometry of the structure (e.g. through the (geometrical) slenderness of the structure, being the ratio $\mathrm{L} / \mathrm{H}$ between the dimensions of the smallest window in which the structure can be included, $\mathrm{L} / \mathrm{H}>1$, or on the geometry of the transverse sections of the structural components through what one calls form factors.

As either volume indicator $\mathrm{W}$ or displacement indicator $\Delta$ allow to find structures of minimum volume, resp. maximal stiffness $(=$ with minimal deflection), it should be logical to consider their use in the determination of limit spans of different structural typologies.

This study is considering the problem for both iso- and hyperstatic arches and cables, necessitating an essentially different approach, as cables are only subject to traction, whereas arches are subject to compression and possible instability phenomena have thus to be taken into account.

The volume indicator $\mathrm{W}$ can be expressed as:

$$
W \stackrel{\Delta}{=} \frac{\sigma V}{F L}=\text { function }\left(\frac{L}{H}, \Psi\right) \quad \text { with } \quad \Psi \stackrel{\Delta}{=} \frac{\mu \sigma L}{\sqrt{q E F}}
$$

in which expression $\Psi$ is the buckling indicator, introduced by Latteur [3] carrying the information about the impact of possible buckling phenomena on the total volume of the structure. The value $\sigma$ is the limit strength of the material 
and is depending on both the type of material and the type of calculation, be it elastic or nonlinear.

Finally, it is useful to remind the three morphological indicators which were named "form factors" and characterising the geometry of the transverse sections of the elements. Those dimensionless numbers are defined by:

$$
q=\frac{I}{\Omega^{2}} \quad \mathrm{Z}=\frac{\Omega h^{2}}{16 I} \quad s=\frac{\Omega}{h^{2}}
$$

Figures $1-3$ show the values of these form factors for eg. tubular sections.

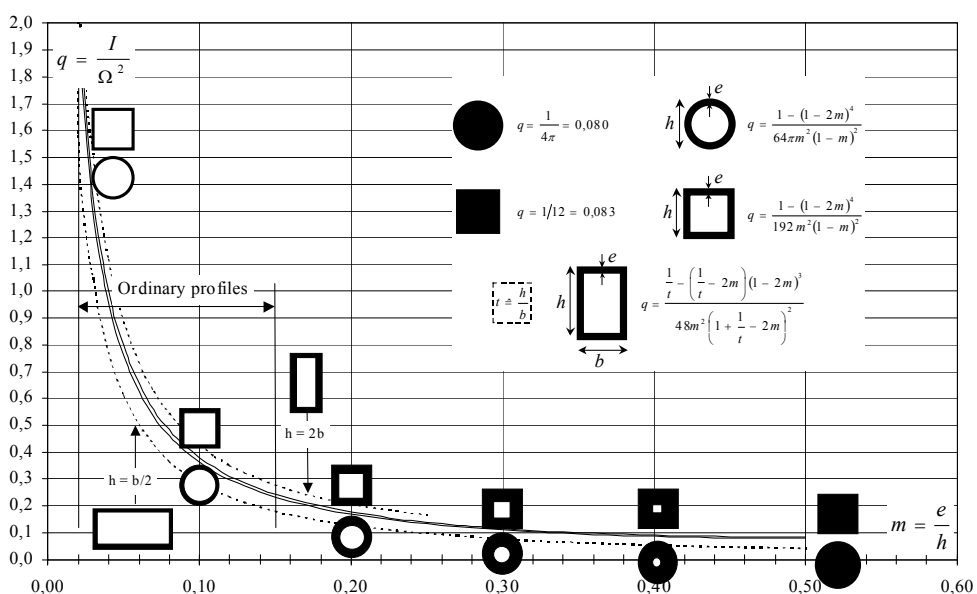

Figure 1: Graph of $q=I / \Omega^{2}$

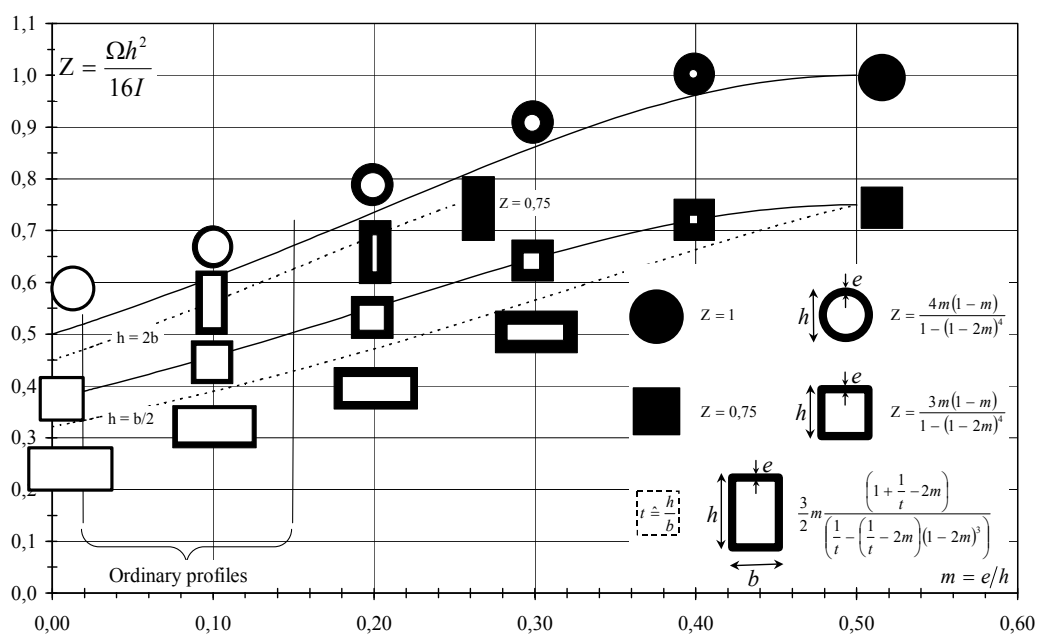

Figure 2: $\quad$ Graph of $Z=\Omega h^{2} / 16 I$. 


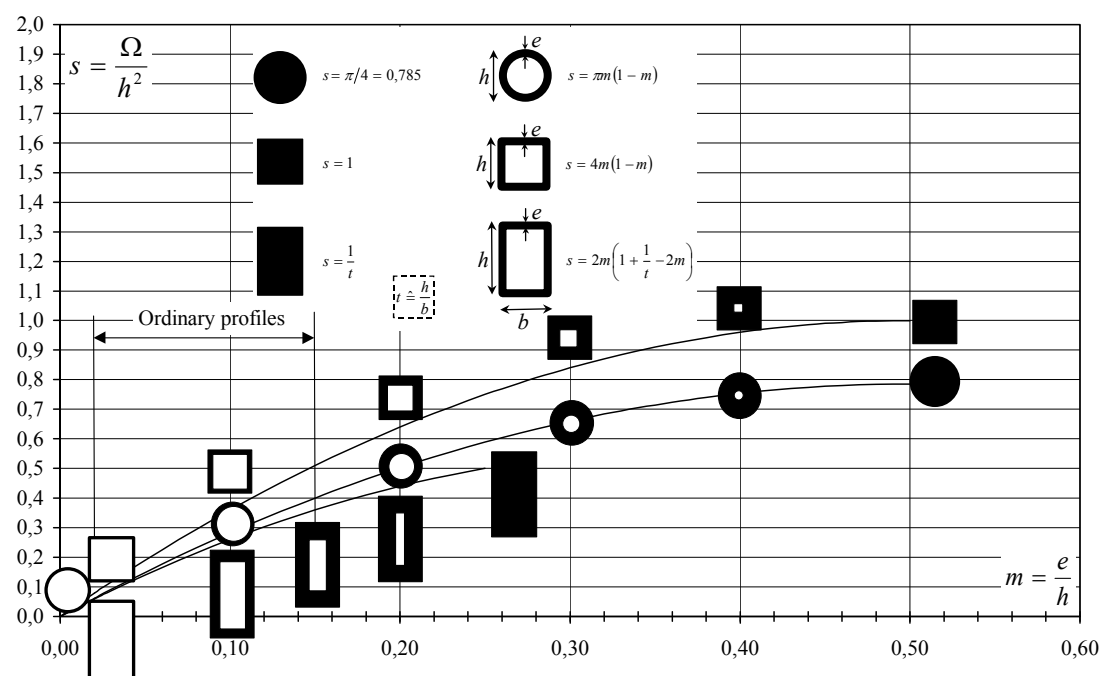

Figure 3: $\quad$ Graph of $s=\Omega / h^{2}$.

\section{Limit span of cables}

A large span cable, when subject to its own weight takes the form of a catenary curve. On the other hand, a cable in a suspension bridge can, if the self-weight of the cable is not dominant, be assimilated with a parabolic curve.

In this context one can establish a first calculation of limit spans on the basis of parabolic curves, but a second calculation should also be achieved on the basis of a catenary form, in order to compare and assess the results.

\subsection{Hypothesis 1: the cable can be assimilated with a parabola}

As a cable structure can only support traction, its volume indicator $\mathrm{W}$ can be found by taking $\mathrm{W}$ for an arch with constant section, loaded in pure compression, neglecting buckling for the latter $[2, \S 4.1$, end of page]:

$$
\begin{aligned}
& W=\frac{\sigma V}{F L}=W^{(L / H)}, \text { in which: } \\
& W^{(L / H)}=\frac{1}{16} \frac{L}{H} \sqrt{1+16\left(\frac{H}{L}\right)^{2}}\left(\sqrt{1+16\left(\frac{H}{L}\right)^{2}}+\frac{L}{4 H} \ln \left(\frac{4 H}{L}+\sqrt{1+16\left(\frac{H}{L}\right)^{2}}\right)\right)
\end{aligned}
$$

$\mathrm{W}$ depends only on the value of the slenderness $\mathrm{L} / \mathrm{H}$ en reaches a minimum for $\mathrm{L} / \mathrm{H}=2,926$. Self-weight is $\rho \mathrm{V}$ and assumed to be uniformly distributed, which yields:

$$
\frac{\sigma V}{(F+\rho V) L}=W^{(L / H)}
$$


If one now defines $\varepsilon=F /(\rho V)$ being the ratio between the resultant of externally applied loads $\mathrm{F}$ and the self-weight:

$$
\frac{\sigma}{(1+\varepsilon) \rho L}=W
$$

which yields a value for the limit span when $\varepsilon \rightarrow 0$ :

$$
L_{\max }=\frac{1}{(1+\varepsilon)}\left(\frac{\sigma}{\rho}\right) \frac{1}{W}
$$

and thus:

$$
L_{\lim }=\frac{\sigma}{\rho} \frac{1}{W}
$$

Fig. 4 shows the limit values for the previously defined materials. These can be corrected in function of the value taken by $\varepsilon=F /(\rho V)$ :

$$
\begin{aligned}
\left(\frac{1}{1+\varepsilon}\right) & =0,91 \quad \text { for } \varepsilon=10 \% \\
& =0,83 \text { for } \varepsilon=20 \% \\
& =0,67 \quad \text { for } \varepsilon=50 \% \\
& =0,50 \text { for } \varepsilon=100 \% \\
& =0,33 \text { for } \varepsilon=200 \% \\
& =0,17 \text { for } \varepsilon=500 \% \\
& =0,09 \text { for } \varepsilon=1000 \%
\end{aligned}
$$

One can also rewrite the above expression, thus finding the value of $\varepsilon$ for a given span:

$$
\varepsilon=\left(\frac{\sigma}{\rho}\right) \frac{1}{L W}-1
$$

For any material, the maximum span $\mathrm{L}_{\lim }$ of a cable is found for $\mathrm{L} / \mathrm{H}=2,926$ :

- for VHS steel $\left(\sigma=1000 \mathrm{Mpa}, \rho=77 \mathrm{kN} / \mathrm{m}^{3}\right): \mathrm{L}_{\text {lim }}=16707 \mathrm{~m}$;

- for HS steel $\left(\sigma=300 \mathrm{Mpa}, \rho=77 \mathrm{kN} / \mathrm{m}^{3}\right): \mathrm{L}_{\lim }=5012 \mathrm{~m}$;

- for mild steel $\left(\sigma=140 \mathrm{Mpa}, \rho=77 \mathrm{kN} / \mathrm{m}^{3}\right): \mathrm{L}_{\mathrm{lim}}=2339 \mathrm{~m}$;

- for aluminium $\left(\sigma=55 \mathrm{Mpa}, \rho=27 \mathrm{kN} / \mathrm{m}^{3}\right): \mathrm{L}_{\text {lim }}=2622 \mathrm{~m}$;

Those spans decrease dramatically for larger or lower values of $\mathrm{L} / \mathrm{H}$.

Remark: one of the longest span of a cable car today is that of Trockener Steg, Switzerland and has a span of $2900 \mathrm{~m}$ for a value $\mathrm{L} / \mathrm{H}=9$.

Fig. 4 shows that for $\mathrm{L} / \mathrm{H}=9$ and the selected materials, the limit span is $10000 \mathrm{~m}$. However, applying the stress reduction factor of 3 (uncertainties about loads, fatigue, material uncertainties...) one finds a limit span of $3333 \mathrm{~m}$, which proves that the design engineers produced a nearly optimal design. Let us also draw the attention on the fact that nowadays limit stress values are increased to approx. $2000 \mathrm{MPa}$. 


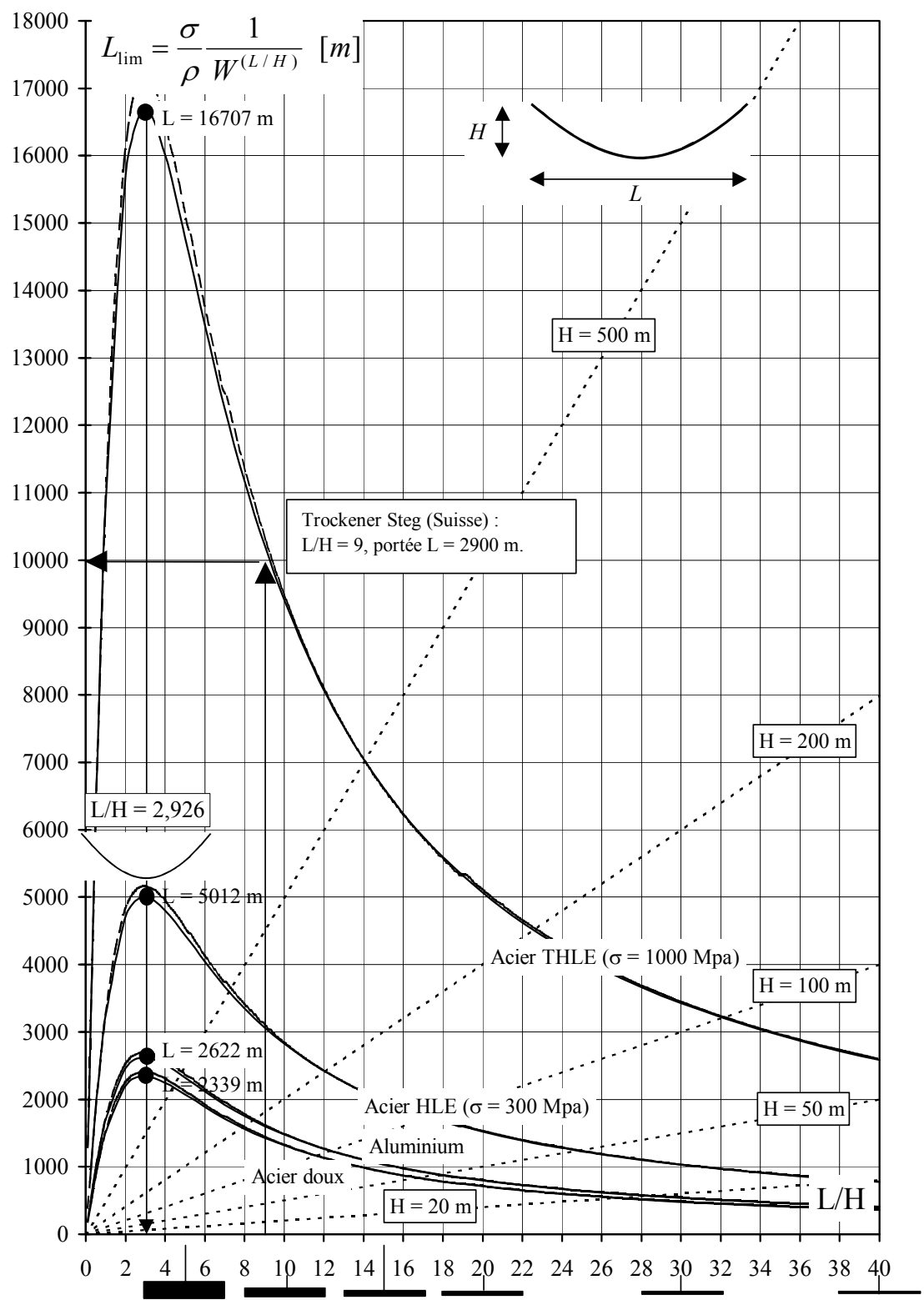

Figure 4: Limit span of cables; continuous lines: hypothesis "parabolic cable" and in long dotted lines: hypothesis "catenary cable". (acier doux $=$ mild steel; portée $=$ span; Acier THLE $=$ VHS steel; Acier HLE = HS steel). 


\subsection{Catenary cable form}

A cable which is only subject to its self-weight takes the form of a catenary. If $\mathrm{R}$ is representing the thrust force (horizontal component of the reaction at the abutments), one can write following equations:

$$
\text { Total length of the cable: } L_{0}: \quad L_{0}=\frac{2 R}{m g} \operatorname{SinHyp}\left(\frac{m g L}{2 R}\right)
$$

Deflection of the cable $y: y(x)=\frac{R}{\rho \Omega}\left(\operatorname{CosHyp}\left(\frac{\rho \Omega L}{2 R}\right)-\operatorname{CosHyp}\left[\frac{\rho \Omega}{R}\left(\frac{L}{2}-x\right)\right]\right)$

$$
\text { Normal force in the cable: } N(x)=R \cdot \operatorname{Cos} H y p\left[\frac{\rho \Omega}{R}\left(\frac{L}{2}-x\right)\right]
$$

Local coordinate on the cable: $s(x)=\frac{R}{\rho \Omega}\left(\frac{\rho \Omega L_{0}}{2 R H}-\operatorname{SinHyp}\left[\frac{\rho \Omega}{R}\left(\frac{L}{2}-x\right)\right]\right)$

If $\Omega$ is the (constant) cable section, the limit span is reached when

$$
N(x=0)=\sigma \Omega
$$

Equation (2) transforms into:

$$
\frac{H}{L}=\beta_{1}\left(\operatorname{CosHyp}\left(\frac{1}{2 \beta_{1}}\right)-1\right),
$$

in which $\beta_{1}=\frac{R}{\rho \Omega L}$ is a solution of the implicit equation. Eqn (3) then becomes:

$$
\beta_{2}=\operatorname{Cos} H y p\left[\frac{1}{2 \beta_{1}}\right],
$$

with $\beta_{2}=\frac{N(x=0)}{R}$ as a solution of this equation.

If one notes that $\beta_{1} \beta_{2}=\frac{N(x=0)}{\rho \Omega L}$, condition eqn (5) transforms into:

$$
L_{\lim }=\frac{\sigma}{\rho} \frac{1}{\beta_{1} \beta_{2}} \quad \text { and } \quad L_{\max }=\frac{1}{(1+\varepsilon)}\left(\frac{\sigma}{\rho}\right) \frac{1}{\beta_{1} \beta_{2}}
$$

This relation defines the curves in long dotted lines in fig. 4: they undoubtedly prove that the approximation of the deflection by a parabola is both safe and very acceptable. 


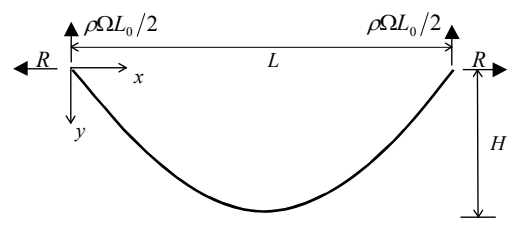

Figure 5: Catenary cable form.

\section{Limit spans of arches}

Fig 6 shows the ratio between $1_{\text {arc }}$, the length of the arch, and its span L, which one can call $\mathrm{g}(\mathrm{L} / \mathrm{H})$ and which only depends on the slenderness $\mathrm{L} / \mathrm{H}$.

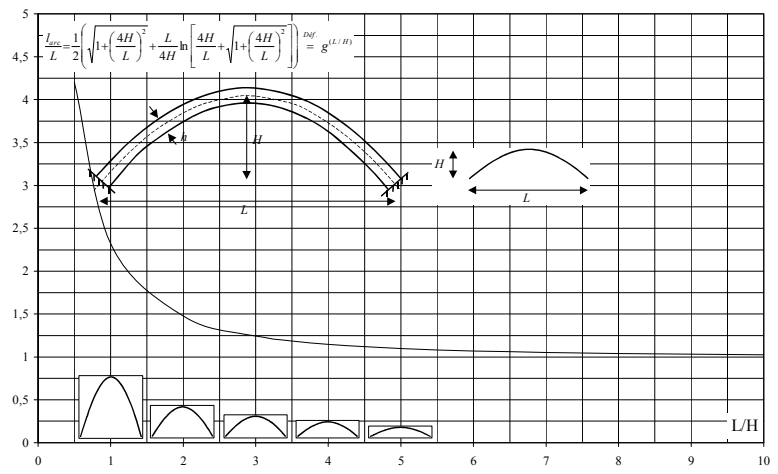

Figure 6: $\quad l_{a r c} / \mathrm{L}=\mathrm{g}^{(\mathrm{L} / \mathrm{H})}$ is shown as a function of the slenderness.

The limit span is studied from the point of view of strength. Indeed, one shows that the deformation of a uniformly loaded arch is very small, and that strength determines the limit span.

Let one consider parabolic arches with constant section; its volume indicator is $[2$, eqn (4)]:

$$
W=\frac{\sigma V}{F_{t o t} L}=\Psi \cdot W^{(C)}
$$

with $W^{(C)}$ the volume indicator for the elements in compression:

$$
W^{(C)}=\frac{\Delta}{2 \sqrt{\gamma}}\left(\sqrt{1+\left(\frac{4 H}{L}\right)^{2}}+\frac{L}{4 H} \ln \left[\frac{4 H}{L}+\sqrt{1+\left(\frac{4 H}{L}\right)^{2}}\right]\right)=\text { Function }(L / H)
$$

where parameter $\gamma$ takes the type of arch into account and is only dependent on the $\mathrm{L} / \mathrm{H}$ ratio:

$$
F=\gamma \frac{E I}{L^{2}}
$$


As the buckling indicator $\Psi=\sigma L / \sqrt{q E F_{t o t}}$ and the total load (self-weight incl.) $F_{t o t}=F+\rho V$, the above expression becomes:

$$
\frac{\sigma V}{(F+\rho V) L}=\frac{\sigma L}{\sqrt{q E(F+\rho V)}} \cdot W^{(C)}
$$

As the total load $\mathrm{F}$ is a fraction $\mathrm{F}=\varepsilon(\rho \mathrm{V})$ of the total self-weight:

$$
\frac{1}{(1+\varepsilon) \rho L}=\frac{L}{\sqrt{q E(1+\varepsilon) \rho V}} \cdot W^{(C)}
$$

which can be rewritten:

$$
L^{2}=\sqrt{\frac{E}{\rho}} \sqrt{\frac{1}{(1+\varepsilon)}} \frac{1}{W^{(C)}} \sqrt{q V}
$$

Fig. 6 shows that the total volume $\mathrm{V}$ of the arch with constant section $\Omega$ :

$$
V=\Omega l_{\text {arc }}=\Omega L g^{(L / H)}
$$

And as $q Z=h^{2} / 16 \Omega$, eqn (6) is now:

$$
L^{4}=\frac{E}{\rho} \frac{1}{(1+\varepsilon)} \frac{1}{\left(W^{(C)}\right)^{2}} \frac{h^{2}}{16 Z} L g^{(L / H)}
$$

One finally gets:

$$
L_{\max }=\sqrt[3]{\frac{E}{\rho} \frac{1}{(1+\varepsilon)}\left[\frac{g^{(L / H)}}{16\left(W^{(C)}\right)^{2}}\right] \frac{1}{Z} h^{2}}
$$

The term between square brackets only depends on $\mathrm{L} / \mathrm{H}$. For $\mathrm{L} / \mathrm{H}=4$, the value is:

- $\quad 2,425$ for the three hinged arch;

- $\quad 6,038$ for the clamped arch.

The limit span is found when the arch can only sustain its self-weight, i.e. when $\varepsilon \rightarrow 0$. For $\mathrm{L} / \mathrm{H}=4$, with the two above mentioned values:

$$
\begin{aligned}
& L_{\lim }=1,343 \sqrt[3]{\frac{E}{\rho} \frac{1}{Z} h^{2}} \quad \text { for the } 3 \text { hinged arch } \\
& L_{\lim }=1,821 \sqrt[3]{\frac{E}{\rho} \frac{1}{Z} h^{2}} \quad \text { for the clamped arch }
\end{aligned}
$$




$$
\begin{aligned}
L_{\text {max }, \text { rés. }}=\left(\sqrt[3]{\left(\frac{1}{1+\varepsilon}\right)}\right)(1,343 \text { or } 1,821) \sqrt[3]{\left(\frac{E}{\rho}\right) \frac{1}{Z} h^{2}} \text { with } \sqrt[3]{\left(\frac{1}{1+\varepsilon}\right)} & =0,97 \text { for } \varepsilon=10 \% \\
& =0,94 \text { for } \varepsilon=20 \% \\
& =0,87 \text { for } \varepsilon=50 \% \\
& =0,79 \text { for } \varepsilon=100 \% \\
& =0,69 \text { for } \varepsilon=200 \% \\
& =0,55 \text { for } \varepsilon=500 \% \\
& =0,45 \text { for } \varepsilon=1000 \%
\end{aligned}
$$
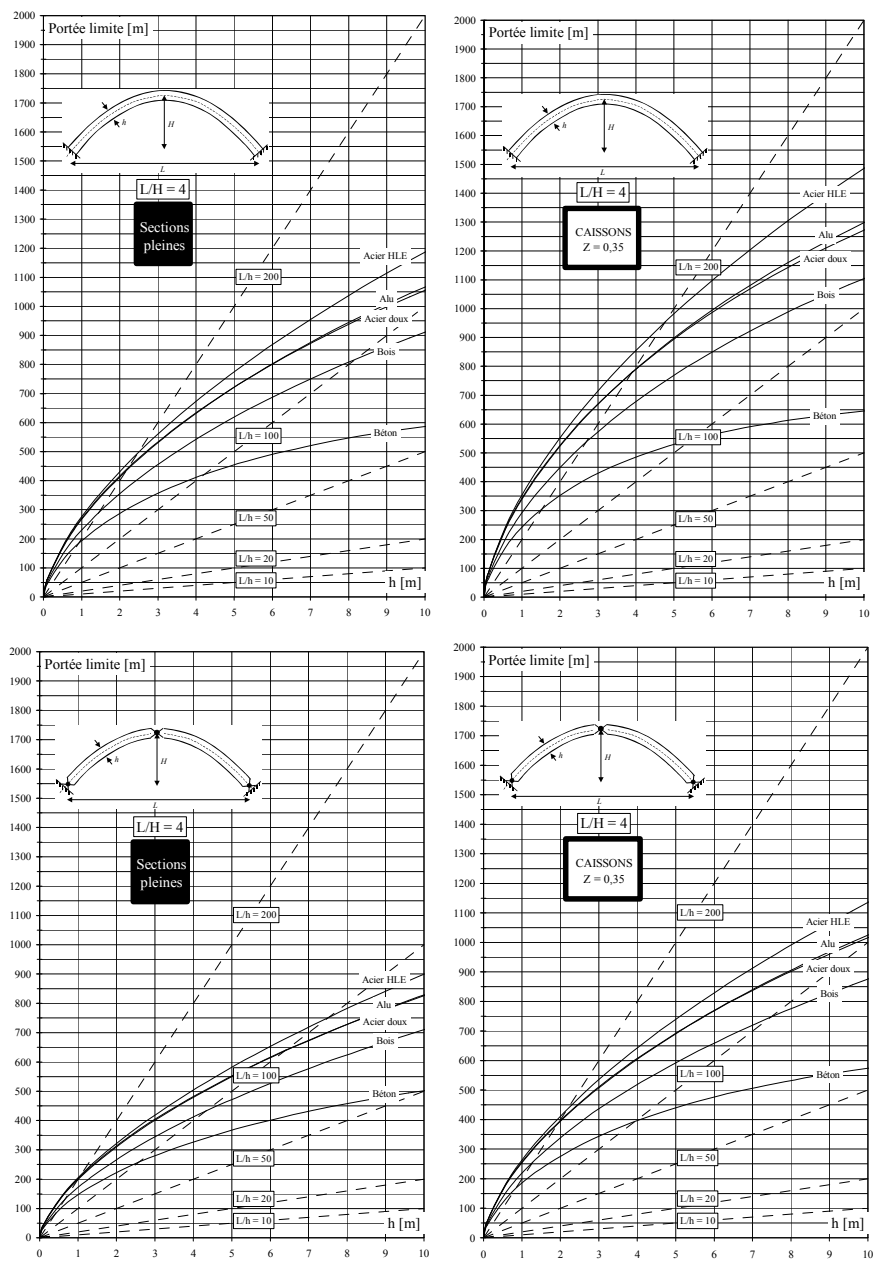

Figure 7: Limit spans of arches with slenderness $\mathrm{L} / \mathrm{H}=4$, in function of $\mathrm{h}$, height of the section (sections pleines $=$ massive sections, caissons $=$ boxes, béton $=$ concrete, bois $=$ timber, portée limite $=$ limit span). 
The values of $E / \rho$ for frequently used materials are:

- for steel: $E / \rho=2727.10^{6}[\mathrm{~mm}], \quad\left(\mathrm{E}=210000 \mathrm{Mpa}, \rho=77 \mathrm{kN} / \mathrm{m}^{3}\right)$;

- for aluminium: $E / \rho=2592.10^{6}[\mathrm{~mm}], \quad\left(\mathrm{E}=70000 \mathrm{Mpa}, \rho=27 \mathrm{kN} / \mathrm{m}^{3}\right)$;

- for timber: $E / \rho=1670.10^{6}[\mathrm{~mm}], \quad\left(\mathrm{E}=10000 \mathrm{Mpa}, \rho=6 \mathrm{kN} / \mathrm{m}^{3}\right)$;

- for reinforced or prestressed concrete: $\quad E / \rho=600.10^{6}$ till $1200.10^{6}$ [mm], $\left(\mathrm{E}=15000 \ldots 30000 \mathrm{Mpa}, \rho=25 \mathrm{kN} / \mathrm{m}^{3}\right)$.

\section{Conclusions}

Morphological indicators are tools which are used by designers in the conceptual design stage. They allow for a suboptimal design of structures and give a preliminary indication of the mechanical possibilities of materials, in the context of structural typologies. The theory allowed to establish good approximations of the limit spans of cable (only traction) and arch (essentially compression and thus sensitive to buckling) structures.

An important conclusion concerns the approximation of the deflection curve of a cable structure by a parabola: this approximation has been shown to be safe and sufficient.

The authors have also applied this theory and established limit spans for beams and classical trusses. These are reported in [3] and could be included in a later paper.

\section{Acknowledgement}

The authors want to acknowledge continuous support of the Scientific Research Board of Vrije Universiteit Brussel in their research.

\section{References}

[1] Latteur P., Samyn Ph., "Optimization of Arches Subjected to Distributed Loads", Proceedings of the IASS International Congress on Shells and Spatial Structures, Vol. I, p. B.3.11-B.3.20, Madrid, Septembre 1999.

[2] Latteur P., Samyn Ph., De Wilde W. P., "Optimisation des arcs paraboliques et en chaînette - aide à la conception sur base d'indicateurs morphologiques", Revue Française de Génie Civil, vol. 5, n 1 , 2001, Hermès, Paris.

[3] Latteur P., "Optimisation et prédimensionnement des treillis, arcs, poutres et câbles sur base d'indicateurs morphologiques - Application aux structures soumises en partie ou en totalité au flambement", Thèse de doctorat, Vrije Universiteit Brussel, Belgique, 2000. 


\section{Other useful references}

- Latteur P., Samyn Ph., "Une méthode globale d'optimisation des treillis", actes du $2^{\text {ième }}$ Congrès Universitaire de Génie Civil, p. 365-372, Poitiers, mai 1999.

- Latteur P., Samyn Ph., De Wilde W. P., "A Search For Efficient Trusses", Proceedings of the International Congress on Shells and Spatial Structures, $\mathrm{p}$. 605-615, Istanbul, Mai 2000.

- Latteur P., Samyn Ph., De Wilde W. P., "Etude du poids et de la raideur des treillis Warren, Pratt et Howe", Revue Française de Génie Civil, vol. 4, n4, 2000, Hermès, Paris. 